\title{
The influence of a thermal bridge in the corner of the walls on the possibility of water vapour condensation
}

\author{
Przemysław Miąsik ${ }^{1, *}$ and Lech Lichołai ${ }^{1}$ \\ ${ }^{1}$ Rzeszow University of Technology, The Faculty of Civil and Environmental Engineering and \\ Architecture, Poznanska 2, 35-082 Rzeszow, Poland
}

\begin{abstract}
The article presents an analysis of temperature on an internal wall surface. Simulations on the external wall corner were also carried out. It is a place where the surface temperature is lower due to the thermal bridge effect. The calculations were performed with the ADINA program used for numerical simulations on heat transfer through divisional structures. Finite element analysis was employed to solve the task. The calculations were performed for five case studies with different corner structures and different methods of insulation. The baseline was a wall with the heat transfer coefficient $\mathrm{U}=0,30 \mathrm{~W} /\left(\mathrm{m}^{2} \mathrm{~K}\right)$. The reason for selecting such a coefficient for analysis was due to the fact that in most Polish buildings thermal resistance of walls results from technical norms from before January 2014. The findings of the numerical simulations were used to determine the maximum relative humidity of the internal air where water vapour condensation may occur on the internal surface of the corner. The calculations were crucial to making a qualitative assessment of the employed solutions. The findings showed that it is possible to improve the thermal functioning of a wall in the corner thanks to an additional layer of thermal insulation, for example in the form of an avant-corps, placed within the corner.
\end{abstract}

\section{Introduction}

The development of civilization and the emergence of new technologies brings with it the need for greater care for the natural environment [1,2]. The production of increasing quantities of products is directly related to the higher consumption of natural resources and increased emission of pollutants into the environment. These processes are inextricably linked with the global increase in energy consumption (needed for the manufacture and supply of products, processing and utilization of waste, etc.) [3]. Therefore, initiatives aimed at rational and economical management of energy resources are important [4]. Reducing $\mathrm{CO}_{2}$ emissions is considered one of the key tasks that we have to face in the near future [5]. In recent years, recommendations of the European Parliament [6, 7] concerning the reduction of $\mathrm{CO}_{2}$ emissions have drawn the attention of constructors to the need to

\footnotetext{
*Corresponding author: pmiasik@prz.edu.pl
} 
reduce heat losses by external building barriers. Recommendations regarding the reduction of the maximum values of heat transfer coefficient $U$ and the methodology for its determination have been introduced into European Standards and national regulations [8-10]. According to currently applicable Polish regulations, the coefficient $U_{\max }=0.23 \mathrm{~W} /\left(\mathrm{m}^{2} \mathrm{~K}\right)$ for external walls (in the case of rooms with an internal temperature of $\mathrm{T}_{\mathrm{i}}>16^{\circ} \mathrm{C}$ ), and after 2021 , this value will be reduced to the level of $\left.0.20 \mathrm{~W} /\left(\mathrm{m}^{2} \mathrm{~K}\right)\right)$. The current state of knowledge on the flow of heat flux through building barriers is very wide. The development of three-dimensional modelling of thermal processes in material structures has resulted in many studies that comprehensively describe the phenomena of heat flow through building barriers. This applies to all groups of buildings: construction of traditional masonry [11, 12] frame construction [13], transparent barriers [14] and those using phase change material [15-18]. Current studies concern both theoretical solutions and their applications in practice $[19,20]$. The existing software used to create numerical models of building structures allows for proper design of building barriers in relation to current technical requirements, including in terms of required thermal insulation.

The aim of this study is to focus on already existing buildings, which are not subject to current requirements, but are still used, and their technical parameters (for example, thermal insulation of walls) often deviate from the requirements for newly created buildings. This article analyses the temperature distribution in the corner of the wall, assuming a value of the heat transfer coefficient for the wall at the level of $U=0.30 \mathrm{~W} /\left(\mathrm{m}^{2} \mathrm{~K}\right)$, i.e. for existing buildings that were created in Poland before January 2014.

\section{Materials and methods}

In the case of the corner of an external wall, the surface temperature of the inner wall decreases. This is due to the fact that in the corner the outer surface (which is in contact with cold air) is larger than the internal surface (heated by warm air) (Fig. 1). In order to determine the negative impact of this phenomenon, several variants of the outer wall corner were analyzed.

\section{$\mathrm{T}_{\mathrm{e}}=-20^{\circ} \mathrm{C}$}
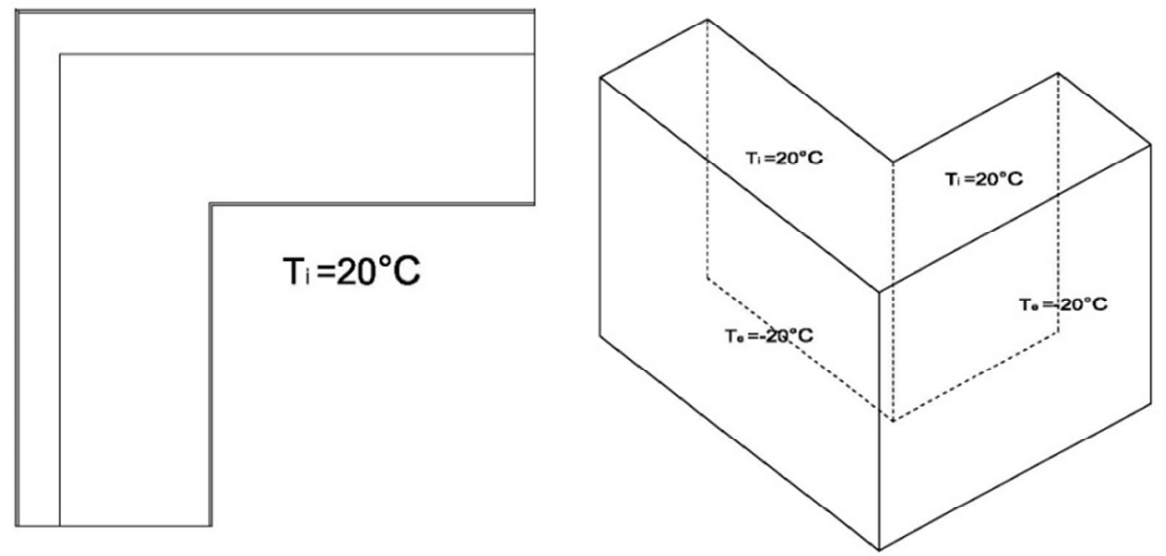

Fig. 1. Horizontal projection and the axonometric drawing of the outer wall of a building.

Using the finite element method (FEM), several configurations of the corner of the outer wall were modelled. External and internal surfaces were subjected to convection and radiation phenomena. On this basis, the temperature distribution in the barrier was determined. The aim was to determine the temperature value of the inner surface of the 
corner and the corresponding calculated value of the relative humidity of the internal air $\varphi_{i}$, at which surface condensation would occur. In all analysed cases, the external air temperature was assumed $\mathrm{T}_{\mathrm{e}}=-20^{\circ} \mathrm{C}$ and the internal air temperature $\mathrm{T}_{\mathrm{i}}=+20^{\circ} \mathrm{C}$.

Simulation calculations were carried out for six calculation options:

- Variant 1: Middle section of the wall. Wall construction with MAX block $288 \mathrm{~mm}$, insulation: styrofoam $80 \mathrm{~mm}$, finish: thin-layer plaster $5 \mathrm{~mm}$,

- Variant 2: Corner. Wall structure as in option 1,

- Variant 3: Corner. Wall structure as in option 2, in the corner instead of the wall there is a reinforced concrete core with the width of the structural wall,

- Variant 4: Corner. Structure of the wall as in option 3, additional insulation with a width of $600 \mathrm{~mm}$ in a corner with a thickness of $80 \mathrm{~mm}$,

- Variant 5: Corner. Structure of the wall as in option 3, additional insulation with a width of $1,000 \mathrm{~mm}$ in a corner with a thickness of $80 \mathrm{~mm}$,

- Variant 6: Corner. Structure of the wall as in option 5, break in additional insulation with a height of $100 \mathrm{~mm}$, spacing every $1,100 \mathrm{~mm}$.

\section{Results and discussion}

In order to check whether the numerical model gives correct results and the assumed boundary conditions are defined correctly - the internal surface temperature value was determined for the central wall section, using analytical calculations. In the case of the middle section of the wall made up of homogeneous layers - the heat flux penetrating through the barrier is perpendicular to the surface of this barrier. For this element, standard values [8] of heat transfer resistance were assumed: on the internal surface $\mathrm{R}_{\mathrm{si}}=0.13 \mathrm{~m}^{2} \mathrm{~K} / \mathrm{W}$ and on the outside surface $\mathrm{R}_{\mathrm{se}}=0.04 \mathrm{~m}^{2} \mathrm{~K} / \mathrm{W}$. The following parameters were also assumed: $U=0.30 \mathrm{~W} /\left(\mathrm{m}^{2} \mathrm{~K}\right)$ and the load of outside air temperature $\mathrm{T}_{\mathrm{e}}=-20^{\circ} \mathrm{C}$ and internal air temperature $\mathrm{T}_{i}=+20^{\circ} \mathrm{C}$. For such assumptions, the surface temperature of the inner wall was calculated:

$$
\begin{gathered}
U=\frac{1}{R_{T}} \Leftrightarrow R_{T}=\frac{1}{U} \\
R_{T}=\frac{1}{0,30 \frac{W}{m^{2} \cdot K}}=3,333 \frac{\mathrm{m}^{2} \cdot K}{W} \\
T_{s i}=T_{i}-\left(T_{i}-T_{e}\right) \cdot \frac{R_{s i}}{R_{T}} \\
T_{s i}=20^{\circ} \mathrm{C}-\left(20^{\circ} \mathrm{C}-\left(-20^{\circ} \mathrm{C}\right)\right) \cdot \frac{0,130 \frac{\mathrm{m}^{2} \cdot K}{\mathrm{~W}}}{3,333 \frac{\mathrm{m}^{2} \cdot \mathrm{K}}{\mathrm{W}}}=18,44^{\circ} \mathrm{C}
\end{gathered}
$$

The computational value of the relative humidity of the internal air $\varphi_{\mathrm{i}}$ was determined, at which surface condensation of water vapor would occur. The obtained value $\varphi_{i}=90.90 \%$ indicates a very low probability of condensation. Then, calculations were made in the numerical model and the results were convergent with the values determined manually. The temperature value on the inner surface of the wall centre was as expected $\mathrm{T}_{\text {si } 1}=18.42^{\circ} \mathrm{C}$ (Fig. 2). 


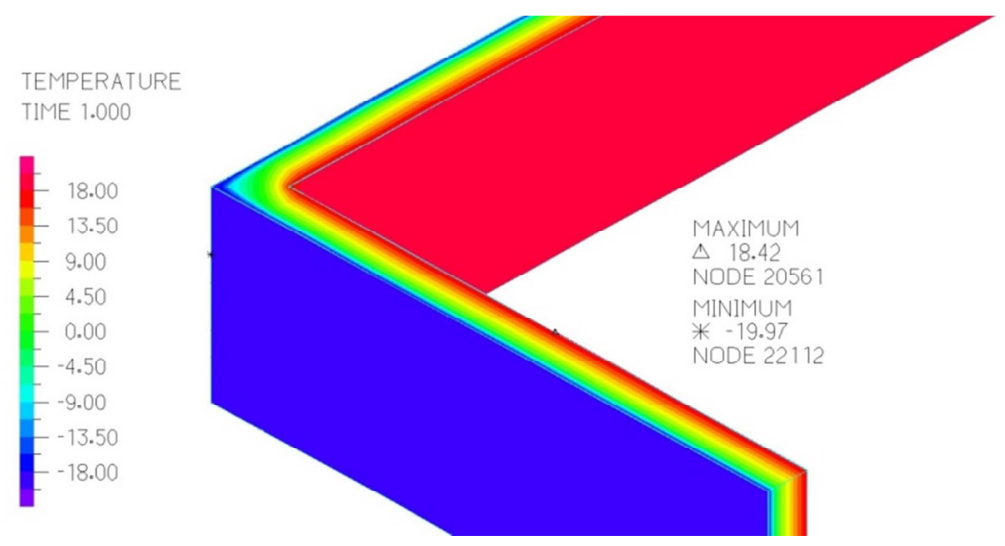

Fig. 2. Temperature values in the central wall zone for variant 1 .

For the same wall structure, the temperature value on the inner surface of the wall corner was $\mathrm{T}_{\mathrm{si} 2}=15.92^{\circ} \mathrm{C}$ (Fig. 3).
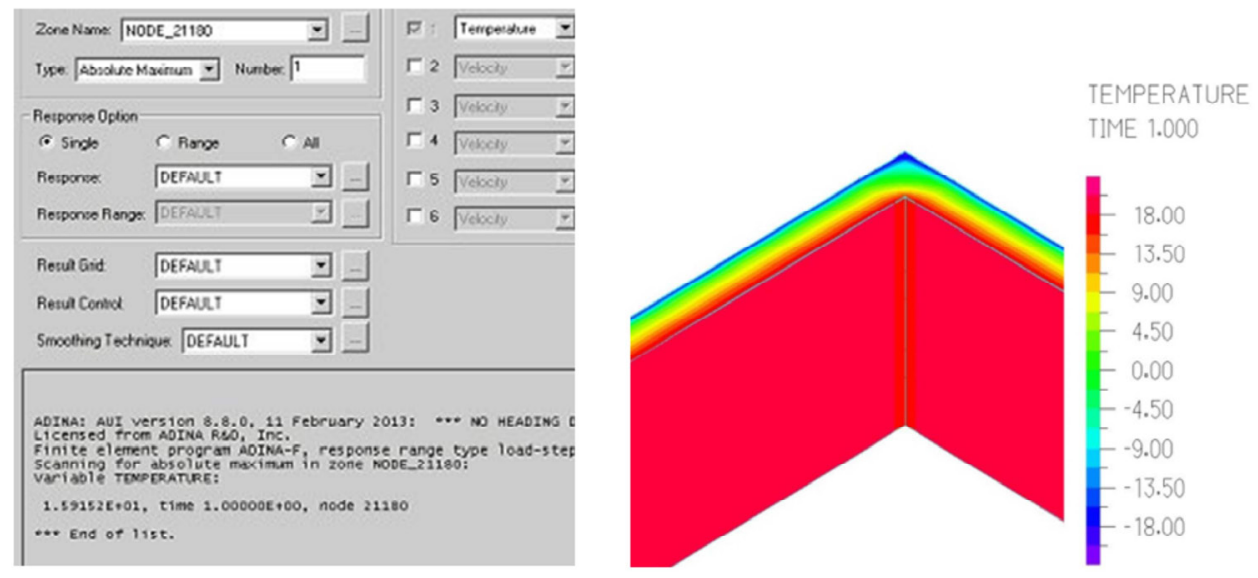

Fig. 3. Temperature values in the corner for variant 2 .

As is apparent from the obtained results, the temperature on the inner surface of the corner was lower in relation to the value occurring in the central part of the wall by $2.50{ }^{\circ} \mathrm{C}$. For such a temperature value, condensation would occur on the internal surface at the value of relative air humidity at the level of $\varphi_{\mathrm{i}}=77.51 \%$. This is still relatively high, and the probability of surface condensation is low.

The situation changes significantly when we additionally deal with a corner zone with a deterioration of the thermal conditions resulting from the use of, for example, a reinforced concrete core. This variant occurs, for example, in buildings with a frame structure. In model No. 3, a reinforced concrete column instead of a wall was used in the corner. A width of the reinforced concrete column equal to the wall thickness was assumed. The space between the columns is still filled with a ceramic wall. The external thermal insulation and plaster finishing remain unchanged, as in option 1. Thermal calculations of model 3 showed a significant decrease in the temperature value in the corner. The lowest value of the internal surface temperature was $\mathrm{T}_{\mathrm{si3}}=11.16^{\circ} \mathrm{C}$ (Fig. 4). 


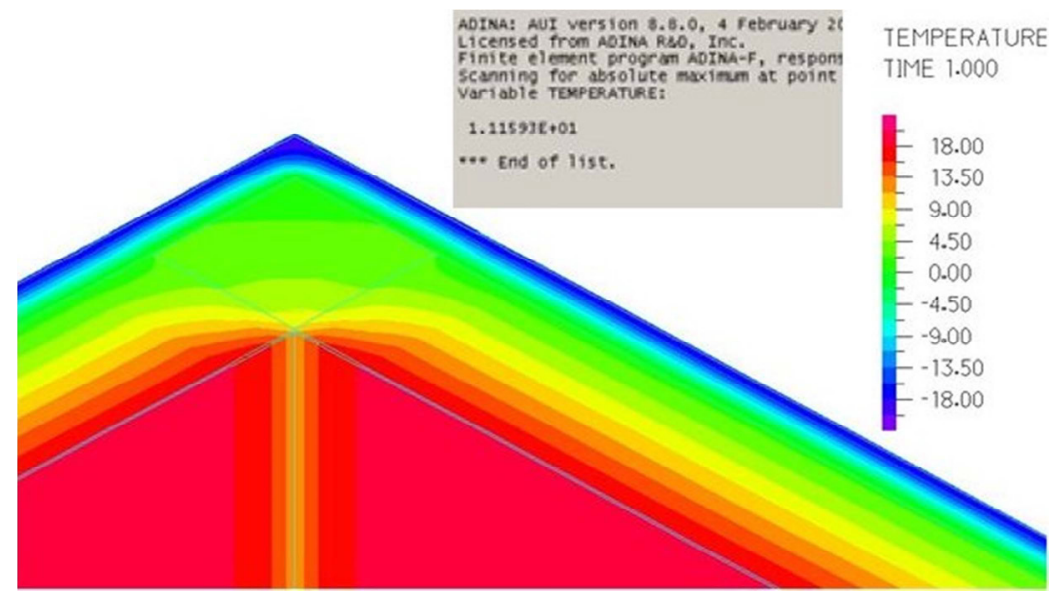

Fig. 4. Temperature values in the corner for variant 3.

For this temperature value, condensation would occur on the inner surface at the relative humidity $\varphi_{\mathrm{i}}=56.86 \%$. The probability of condensation in this case is large. This applies in particular to rooms with high temporary water vapor saturation, such as: kitchen, bathroom, laundry, drying room, etc. It should also be noted that in practice the surface temperature of the wall may be even lower due to, for example, the occurrence of built-in housings, devices, etc. In order to prevent the condensation of water vapor, the temperature of the corner of the external wall should be raised. In model 4, additional corner insulation is used from the outside. The insulation was made of styrofoam $80 \mathrm{~mm}$ thick. The width of the projection from the outside was assumed to be $600 \mathrm{~mm}$. Thermal calculations of model 4 showed the lowest value of the internal temperature in the corner at $\mathrm{T}_{\mathrm{si} 4}=12.81^{\circ} \mathrm{C}$ (Fig. 5).

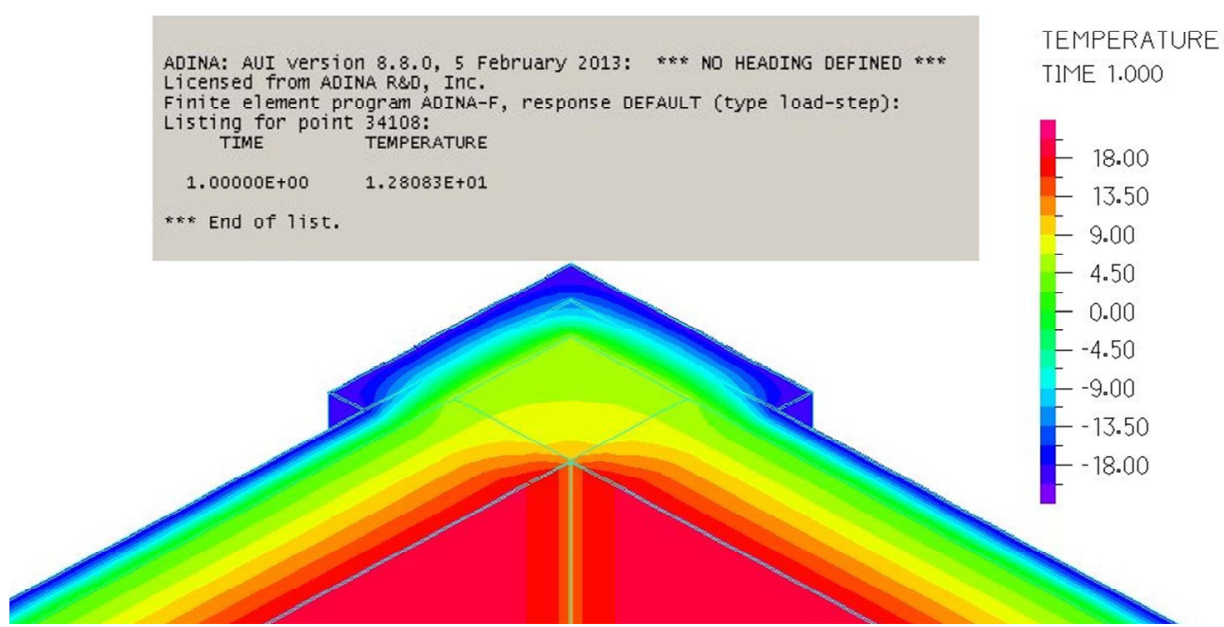

Fig. 5. Temperature values in the corner for variant 4.

In relation to the results obtained for case 3 , the value of the minimum internal surface temperature increased by $1.65^{\circ} \mathrm{C}$. This results in raising the maximum permissible relative humidity to the level of $\varphi_{\mathrm{i}}=63.39 \%$. This is not a satisfactory value. The small effect of the impact of additional insulation results from too narrow a strip insulating the corners.

In model 5, an additional $80 \mathrm{~mm}$ thick insulation was used, similar to model 4 . This time the width of the external projection is $1,000 \mathrm{~mm}$. The results of the calculations 
indicate a satisfactory effect. For variant 5 , the minimum temperature of the inner surface in the corner is $\mathrm{T}_{\mathrm{si5}}=15.29^{\circ} \mathrm{C}$ (Fig. 6). The obtained value is higher by $4.13^{\circ} \mathrm{C}$ in relation to that obtained for model 3 .

ADINA: AUI version 8.8.0, 11 February Licensed from ADINA R\&D, Inc.

Finite element program ADINA-F, respc scanning for absolute maximum at poir variable TEMPERATURE:

1.52874E+01, time $1.00000 E+00$

*** End of list.

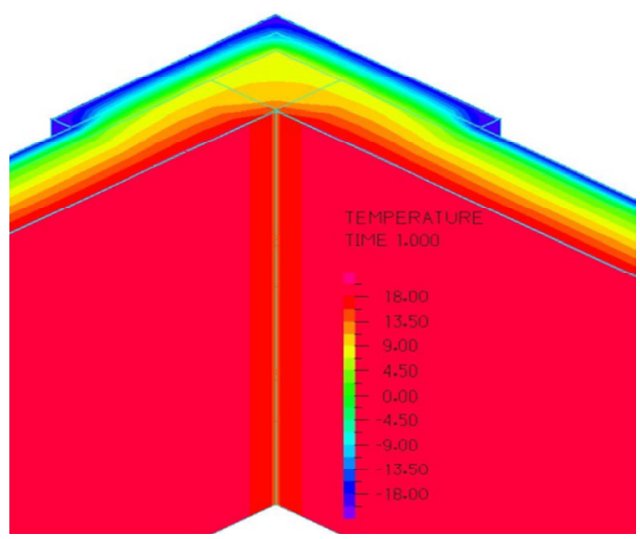

Fig. 6. Temperature values in the corner for variant 5 .

The temperature of the inner surface of the corner, obtained in variant 5 is similar to that which occurred in the case of the 2 , which did not contain a thermal bridge in the form of a reinforced concrete column. For such a value of the surface temperature of the inner wall, condensation of water vapor will only occur after exceeding the relative humidity $\varphi_{i}=74.44 \%$.

Variant No. 6 contains the version of the "segmented" projection. In this version, an additional layer of corner insulation is realized in the form of corner squares with a side of $1,000 \mathrm{~mm}$, separated from each other by a distance of $100 \mathrm{~mm}$ (Fig. 7). This form of projection is intended to improve the visual effect of the façade. The purpose of the analysis is to check how a $100 \mathrm{~mm}$ gap in additional insulation affects the minimum temperature drop on the inner surface in the corner. As a result of the calculations carried out for case 6 , the minimum temperature of the inner surface of the corner at point 50860 was obtained. The obtained value $\mathrm{T}_{\mathrm{si} 6}=14.48^{\circ} \mathrm{C}$ (Fig. 7) is $0.77^{\circ} \mathrm{C}$ lower than that obtained for case 5 , but $1.67^{\circ} \mathrm{C}$ higher than the minimum value, obtained as a result of calculations of case 4 . For this value of the surface temperature of the inner wall, condensation of water vapor will occur only after exceeding the relative humidity $\varphi_{i}=70.66 \%$.

The summary of results obtained for variants $1-6$ is shown in Table 1.
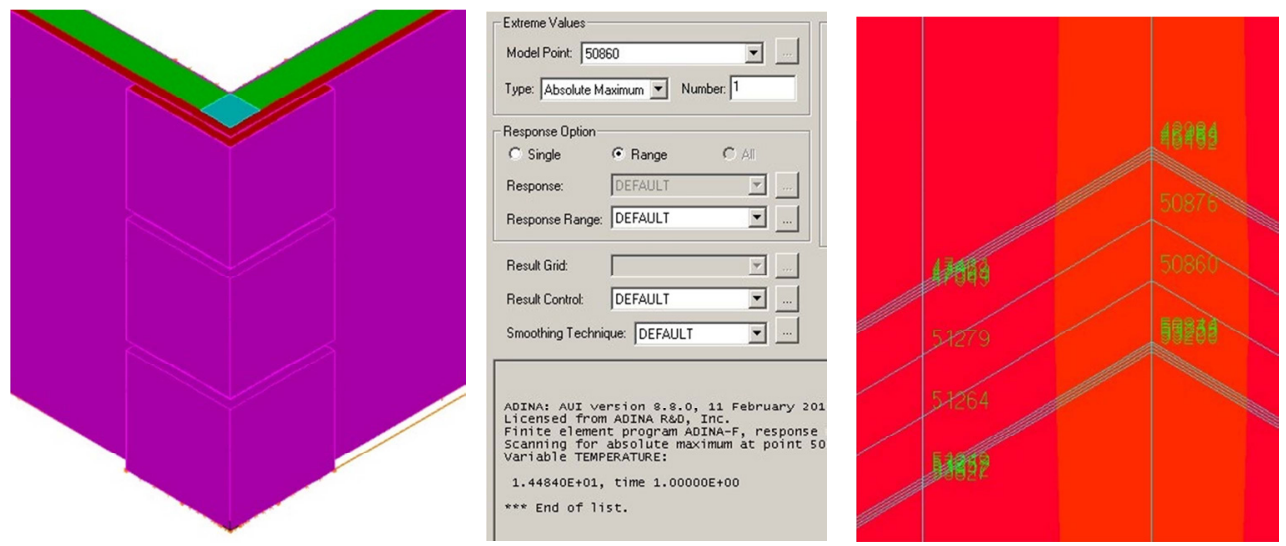

Fig. 7. Temperature values in the corner of the wall for case 6. 
Table 1. Tabular summary of the results obtained for variants 1-6.

\begin{tabular}{|c|c|c|c|c|}
\hline No. & Construction of the barrier & $\begin{array}{c}\text { Analysed } \\
\text { element }\end{array}$ & $\begin{array}{c}\text { Minimum } \\
\text { temperature } \\
\text { value on the } \\
\text { inner surface } \\
{\left[{ }^{\circ} \mathrm{C}\right]}\end{array}$ & $\begin{array}{c}\text { Value of relative } \\
\text { humidity at which } \\
\text { condensation of } \\
\text { water vapor occurs } \\
\text { on the inner surface } \\
\text { [\%] }\end{array}$ \\
\hline 1. & MAX $288 \mathrm{~mm}$ blocks + styrofoam $80 \mathrm{~mm}$ & $\begin{array}{l}\text { Middle } \\
\text { surface }\end{array}$ & +18.42 & 90.90 \\
\hline 2. & MAX $288 \mathrm{~mm}$ blocks + styrofoam $80 \mathrm{~mm}$ & Corner & +15.92 & 77.51 \\
\hline 3. & $\begin{array}{l}\text { MAX } 288 \mathrm{~mm} \text { blocks }+ \text { styrofoam } 80 \mathrm{~mm}+ \\
\text { reinforced concrete core in } 288 \mathrm{~mm} \text { corner }\end{array}$ & Corner & +11.16 & 56.86 \\
\hline 4. & $\begin{array}{l}\text { MAX } 288 \mathrm{~mm} \text { blocks + polystyrene } 80 \mathrm{~mm}+ \\
288 \mathrm{~mm} \text { reinforced concrete core in the } \\
\text { corner + corner insulation } 600 \mathrm{~mm} \text { wide }\end{array}$ & Corner & +12.81 & 63.39 \\
\hline 5. & $\begin{array}{l}\text { MAX } 288 \mathrm{~mm} \text { blocks }+ \text { polystyrene } 80 \mathrm{~mm}+ \\
288 \mathrm{~mm} \text { reinforced concrete core in the corner } \\
+ \text { corner insulation with a width of } 1000 \mathrm{~mm}\end{array}$ & Corner & +15.29 & 74.44 \\
\hline 6. & $\begin{array}{l}\text { MAX } 288 \mathrm{~mm} \text { blocks }+ \text { styrofoam } 80 \mathrm{~mm}+ \\
288 \mathrm{~mm} \text { reinforced concrete core in corner }+ \\
\text { corner segment insulation (insulation } 1000 \mathrm{~mm} \\
+ \text { vertical break } 100 \mathrm{~mm} \text { ) }\end{array}$ & Corner & +14.48 & 70.66 \\
\hline
\end{tabular}

\section{Conclusions}

The calculations show that in the case of external walls, the surface temperature of the inner wall in the corner is significantly reduced. This applies especially to framework constructions in which construction columns are also thermal bridges. This adversely affects the properties of the barrier, it gives the possibility of water vapor condensing on its surface or inside it. This process may lead to increased conduction and, as a result, increased heat energy losses, the formation of fungal processes or reduced mechanical properties of the structure. In order to improve the temperature distribution in the corner and to avoid the condensation of water vapor, it is reasonable to use an increased layer of thermal insulation of the corner, for example in the form of breaks. The effectiveness of additional corner insulation depends on the minimum required additional insulation width. Its value should result from computational simulations. The use of segment projection lowers the temperature of the corner to a small extent and can be successfully implemented e.g. during thermal renovation of historic buildings. Careful design of thermal insulation of a building not only leads to a significant reduction of energy consumption during its operation, but it also provides users with much better indoor comfort. The use of numerical simulation of temperature distribution in a three-dimensional model of the barrier enables the implementation of energy-saving solutions and minimizes the risk of making design mistakes. The final result is a reduction in the operating costs of a building and sustainable management of energy resources on a macro scale. 


\section{References}

1. F. Grey, J. Environ. Econ. Manag., 90, 23-40, (2018)

2. C. Hamilton, A. Macintosh, Environmental Protection and Ecology, Encyclopedia of Ecology, Pages 1342-1350 (2008)

3. T. Huo, H. Ren, X. Zhang, W. Cai, W. Feng, N. Zhou, X. Wang, J. Cleaner Prod., 185, 665-679, (2018)

4. A. Fratean, P. Dobra, Sustain. Cities Soc., 9, 459-475, (2018)

5. F. deLlano-Paz, A. Calvo-Silvosa, S. Iglesias Antelo, I. Soares, J. Cleaner Prod., 181, 123-135, (2018)

6. Directive 2002/91/EC of the European Parliament and of the Council of 16 December 2002 on the energy performance of buildings

7. Directive 2010/31/EU of the European Parliament and of the Council of 19 May 2010 on the energy performance of buildings

8. ISO 6946:2007 Building components and building elements -- Thermal resistance and thermal transmittance -- Calculation method

9. ISO 6946:2017 Building components and building elements -- Thermal resistance and thermal transmittance -- Calculation methods

10. ISO 13788:2012 Hygrothermal performance of building components and building elements - Internal surface temperature to avoid critical surface humidity and interstitial condensation - Calculation methods

11. J. Zach, V. Novák, Procedia Eng., 151, 206-213, (2016)

12. X. Zhou, D. Derome, J. Carmeliet, Build. Environ., 125, 285-298, (2017)

13. Z. Pasztory, P. N. Peralta, I.Peszlen, Energy Build., 43, Issues 2-3, 713-717, (2011)

14. D. Naylor, S.S.M. Foroushani, D. Zalcman, Energy Build., 138, 206-214, (2017)

15. L. Lichołai, J. Krasoń, P. Miąsik, A. Starakiewicz, JCEEA, 64 (1), 495-504, (2017)

16. A. Serrano, A. M. Borreguero, I. Garrido, J. F. Rodríguez, M. Carmona, 103, 226-232, (2016)

17. S. Ramakrishnan, X. Wang, J. Sanjayan, J. Wilson, Energy Procedia, 88 725-731, (2016)

18. A. Sharma, V. V. Tyagi, C. R. Chen, D. Buddhi, Renewable Sustainable Energy Rev. 13, 318-345, (2009)

19. A. Starakiewicz, L. Lichołai, P. Miąsik, JCEEA, 64 (1), 165-172, (2017)

20. A. Starakiewicz, L. Lichołai, P. Miąsik, J. Krasoń, JCEEA, 63 (3), 439-446, (2016) 